\title{
Spatio-temporal network analysis of pig trade to inform the design of risk-based disease surveillance
}

\author{
Nicolás Céspedes Cárdenas ${ }^{1}$, Kimberly Vanderwaal ${ }^{2}$, Flávio Pereira Veloso ${ }^{3}$, Jason Onell \\ Ardila Galvis ${ }^{1}$, Marcos Amaku ${ }^{1,4}$, and José H H Grisi Filho - ${ }^{1}$ \\ ${ }^{1}$ Department of Preventive Veterinary Medicine and Animal Health, School of Veterinary \\ Medicine and Animal Science, University of São Paulo \\ ${ }^{2}$ Department of Veterinary Population Medicine, University of Minnesota \\ ${ }^{3}$ Companhia Integrada de Desenvolvimento Agrícola de Santa Catarina (CIDASC \\ ${ }^{4}$ Department of Pathology, School of Medicine, University of São Paulo
}

November 30, 2020

Nicolás Céspedes Cárdenas ${ }^{1}$, Kimberly VanderWaal ${ }^{2}$, Flávio Pereira Veloso ${ }^{3}$, Jason Onell Ardila Galvis ${ }^{1}$, Marcos Amaku ${ }^{1,4}$, José H. H. Grisi-Filho ${ }^{1}$

${ }^{1}$ Department of Preventive Veterinary Medicine and Animal Health, School of Veterinary Medicine and Animal Science, University of Sao Paulo, Sao Paulo, Brazil

${ }^{2}$ Department of Veterinary Population Medicine, University of Minnesota

${ }^{3}$ Companhia Integrada de Desenvolvimento Agricola de Santa Catarina (CIDASC)

${ }^{4}$ Department of Pathology, School of Medicine, University of Sao Paulo, Sao Paulo, Brazil

\begin{abstract}
Network analysis is a powerful tool to describe, estimate, and predict the role of pig trade in the spread of pathogens and generate essential patterns that can be used to understand, prevent, and mitigate possible outbreaks. This study aimed to describe the network of between-farm pig movements and identify heterogeneities in the connectivity of premises in the state of Santa Catarina, Brazil, using social network analysis (SNA). We used static and temporal network approaches to describe pig trade in the state by quantifying network attributes using SNA parameters, such as causal fidelity, loyalty, the proportion of node-loyalty, resilience of outgoing contact chains, and communities. Two indexes were implemented, the first one is a normalized index based on SNA-farm level measures and other index-based SNA-farm level measures considering the swine herd population size from all premises, both indexes were summarized by municipality to target and rank surveillance activities. Within Santa Catarina, the southwest region played a key role in that $80 \%$ of trade was concentrated in this region, and thus acted as a hub in the network. In addition, nine communities were found. The results also showed that premises were highly connected in the static network, with the network exhibiting low levels of fragmentation and loyalty. Also, just $11 \%$ of the paths in the static network existed in the temporal network which accounted for the order in which edges occurred. Therefore, the use of time-respecting-paths was essential to not overestimate potential transmission pathways and outbreak sizes. Compared to static networks, the application of temporal network approaches was more suitable to capture the dynamics of pig trade and should be used to inform the design of risk-based disease surveillance.
\end{abstract}

Introduction 
Infectious diseases in livestock cause great economic losses, block international trade, compromise animal welfare, reduce productivity, and induce large costs through disease control and eradication (BAJARDI et al., 2012; MOSLONKA-LEFEBVRE et al., 2016). In Brazil, the swine industry consists of approximately two million sows and produced 3.76 million tons of meat in 2018, which has made Brazil the fourth-largest producer of pork in the world. Within Brazil, the state of Santa Catarina (SC) is the largest swine producer (EMBRAPA, 2019). The control of infectious diseases is critical to maintaining this leadership, and the movement of animals through trade plays an important role in spreading infectious diseases (SCHULZ et al., 2017).

In recent years, the Brazilian National Veterinary Services (BNVS) has intensified disease surveillance, control, and eradication efforts. Until 2019, SC is the only state in the country free of foot-and-mouth disease (FMD) without vaccination. Therefore, it is critical to understand patterns and risks associated with animal movements to maintain this disease-free status. This is especially relevant for the national efforts to transition from the country-wide status of FMD disease-free with vaccination to without vaccination, which is expected to be achieved by 2023 (MAPA, 2017). In this context, the analysis of contact networks is a powerful tool to describe, predict and estimate the role of trade in the spread of diseases (LEBL et al., 2016; VANDERWAAL et al., 2016a), producing important data to understand, prevent, and mitigate possible outbreaks in the region.

Much of the research on livestock movement networks has used static representations of networks, which assumes that connections among farms are constant and unchanging through time. However, static representations over-represent the network's connectivity (LENTZ; SELHORST; SOKOLOV, 2013). Temporal representations of networks consider the active and inactive connections according to a time interval, which is a more accurate characterization of network patterns (BUTTNER; SALAU; KRIETER, 2016; CHATERS et al., 2019; MACHADO et al., 2020).

The objective of this study was to characterize the dynamics of pig trade, describe both static and temporal movement networks, and provide useful information to target surveillance actions in municipalities and individual premises in the state of Santa Catarina, Brazil, according to their importance in the network. Such rankings, which are based on different parameters derived through social network analysis (SNA), helps to improve the prevention, control, and eradication of communicable diseases spread through animal movements.

\section{Material and methods}

\subsection{Data}

Records of animal movements from Santa Catarina (SC) state in Brazil were provided by the official veterinary service in this state. The database includes the movements of pigs in SC in Brazil from 2015-01-01 to 2017-12-31. Records included all intra-state movements as well as outgoing movements with destinations outside of SC. Records with errors about the origin, destination, date or movements with destinations outside of SC were removed prior to any analysis. For the network analysis, movements with the purpose of slaughter were excluded, which were assumed to be epidemiological endpoints.

\subsection{Trade description}

Premises that moved at least once during the study period were included as nodes in the network; premises for which no movements were recorded were assumed to be inactive. In order to represent the spatial distribution of premises, the number of premises was grouped by geolocation across a $\sim^{2} \mathrm{~km}^{2}$ grid (see figure 1). The production type of each premises was classified according to the records provided by the official surveillance veterinary service. Eight type of premises were classified: Finishers (n = 7119), Breeding-farms $(\mathrm{n}=2255)$, Non-commercial or backyard farms $(\mathrm{n}=2055)$, Nursery farms $(\mathrm{n}=1398)$, Wean-to-finisher \& mixed farms $(\mathrm{n}=447)$, Slaughterhouses $(\mathrm{n}=189)$, Certified-Swine-Breeder-Farms $(\mathrm{n}=138)$, and others premises $(\mathrm{n}=111)$. 


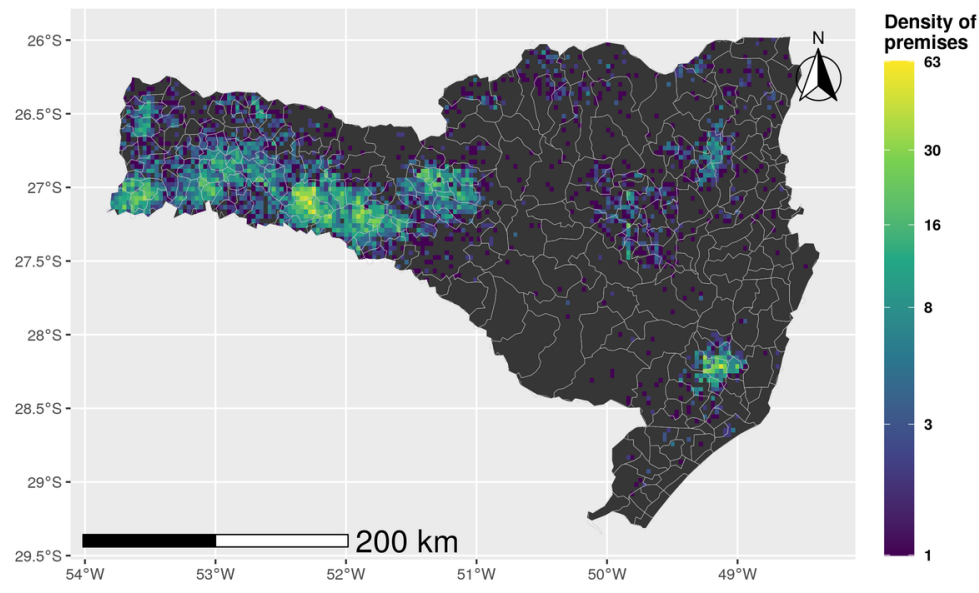

Figure 1. The study area included the state of Santa Catarina, Brazil. A $3 \mathrm{~km}^{2}$ grid was projected onto the map, the density of premises was represented as the number of premises allocated in each grid cell. The black background represents grids without premises. The gray lines represent the municipalities of SC.

In general, Wean-to-finisher $\&$ mixed premises house breeding sows and bores for the production of piglets, which are also fattened on premise for slaughter. This classification also included instances in which premises with more than one type of classification were co-located i.e. farrowing farms and farrow-tofinishing farms.Breeding-farms are premises which deliver piglets to nursery farms and, less frequently, to finishers. Certified-Swine-Breeder-Farm (CSBF) are premises with an official certificate to send animals for breeding purposes. Non-commercialfarms are backyards farms and/or places where subsistence pig farming occurs. Nurseries are a type of premises designed specifically to house newly weaned pigs until they reach the grower/finisher stage. Finishing premises receive piglets from the farrowing farms and deliver fattening pigs to the slaughterhouses. Other premises are those that cannot be incorporated in the previous classification, such as pig events trade, laboratories, or without information.

Movements (including movements with destination to slaughterhouses) to and from different types of premises were analyzed and the number and percentage of movements and total of animals moved were summarized. The number of records by purpose and their state destination (SC and the other Brazilian states) are shown in table 1.

Table 1. Total records and percentage by destination intra- and inter-SC State in Brazil.

\begin{tabular}{lllll}
\hline Purpose of the Movement & Santa Catarina & Santa Catarina & Outgoing movements to outside SC & Outgc \\
\hline & Total of records & \% of records & Total of records & \% of $~$ \\
Slaughter & 435.217 & 57,56 & 41.044 & 64,69 \\
Fattening & 254.394 & 33,65 & 12.224 & 19,27 \\
Reproduction & 66.080 & 8,74 & 10.146 & 15,99 \\
Others & 380 & 0,05 & 36 & 0,06 \\
Total & 756,071 & 100,00 & 63,450 & 100,00 \\
\hline
\end{tabular}

\subsection{Static network}

We constructed contact networks in which premises were defined as nodes and movements between premises were considered edges. The consequent contact network $g$ was based on the movements during the study and was represented as directed $\left(g_{\mathrm{ij}} \neq g_{\mathrm{ji}}\right)$, such that where the origin (node $i$ ) and destination (node $j$ ) have a specific direction. We described the static network using data from all years of study as well as by year. 
Parameters that we measured are summarized in Table 2.

Table 2. Description of network analysis terminology and metrics

\begin{tabular}{|c|c|c|}
\hline Parameter & Definition & Reference \\
\hline Nodes & $\begin{array}{l}\text { The unit of interest in network } \\
\text { analysis, for example, herds or } \\
\text { municipalities. }\end{array}$ & (WASSERMAN; FAUST, 1994) \\
\hline Edge & $\begin{array}{l}\text { Link between two nodes in the } \\
\text { network. }\end{array}$ & \\
\hline Degree $(\mathrm{k})$ & $\begin{array}{l}\text { Number of unique contacts to } \\
\text { and from a specific node (e.g., } \\
\text { farm location). When the } \\
\text { direction is considered, the } \\
\text { ingoing and outgoing contacts } \\
\text { are separated: out-degree is the } \\
\text { number of contacts originating } \\
\text { from a specific node, and } \\
\text { in-degree is the number of } \\
\text { contacts coming into a specific } \\
\text { node. }\end{array}$ & \\
\hline PageRank & $\begin{array}{l}\text { Google PageRank measure, a } \\
\text { link analysis algorithm that } \\
\text { produces a ranking of } \\
\text { importance for all nodes in a } \\
\text { network with a range of values } \\
\text { between zero and one. The } \\
\text { PageRank calculation considers } \\
\text { the indegree of a given premises } \\
\text { and the indegree of its } \\
\text { neighbors. }\end{array}$ & (BRIN; PAGE, 1998) \\
\hline $\begin{array}{l}\text { Reverse of PageRank } \\
(\operatorname{rev}(\text { PageRank }))\end{array}$ & $\begin{array}{l}\text { The Google PageRank } \\
\text { algorithm can be typically } \\
\text { implemented in an adjacent } \\
\text { matrix } \mathbf{A} \text { as a representation of } \\
\text { the directed graph } g \text {. Here, we } \\
\text { use a transposed adjacency } \\
\text { matrix } \mathbf{t}(\mathbf{A}) \text { where } \mathbf{t}(\mathbf{A}) \text { ij }=\mathbf{1} \\
\text { if there exists an edge between } \\
\text { the origin node } \mathbf{i} \text { and } \\
\text { destination node } \mathbf{j} \text {, otherwise } \\
\mathbf{t}(\mathbf{A}) \text { ij }=\mathbf{0} \text { if the edge does not } \\
\text { exist. We then applied the } \\
\text { PageRank algorithm using the } \\
\mathbf{t}(\mathbf{A}) \text { to obtain the } \\
\text { rev(PageRank). }\end{array}$ & \\
\hline In/out Closeness centrality & $\begin{array}{l}\text { Closeness centrality measures } \\
\text { how many steps are required to } \\
\text { access every other vertex from a } \\
\text { given node; this measure can be } \\
\text { calculated for incoming or } \\
\text { outgoing paths. }\end{array}$ & (FREEMAN, 1978) \\
\hline
\end{tabular}


Betweenness

In/out degree centralization

Clustering coefficient

Giant weakly connected component (GWCC)

Giant strongly connected component (GSCC).
Describes the extent to which a node lies on paths connecting other pairs of nodes, defined by the number of geodesics (shortest paths) going through a node.

Quantifies the extent to which a minority of the farms are responsible for a majority of the incoming/outgoing movements. Measures the degree to which nodes in a network tend to cluster together (i.e., if A B and $\mathrm{B} \mathrm{C}$, what is the probability that $\mathrm{A} \mathrm{C}$ ), with a range of values between zero and one. Proportion of nodes that are connected in the largest component when directionality of movement is ignored Proportion of the nodes that are connected in the largest component when directionality of movement is considered
(WASSERMAN; FAUST, 1994)

(WATTS; STROGATZ, 1998)

(WASSERMAN; FAUST, 1994)

(WASSERMAN; FAUST, 1994)

\subsubsection{Fragmentation of the network}

We computed the fragmentation $\mathrm{F}$ of the static network, which measures the proportion of pairs of nodes for which no connecting path exists (no direct or indirect connections between premises). The value can be calculated through an assessment of the number and size of components in the network, where a connected component $C$ is defined as a subset of nodes $V$, where $C \subseteq V$ for which a path exists between any pair of nodes in C. Thus, fragmentation was calculated as:

$$
F=1-\frac{\sum_{k} S_{k}\left(S_{k}-1\right)}{n(n-1)}
$$

Where $S_{k}$ is the number of premises in component $k$ and $n$ the total number of premises in the network. Fragmentation ranges between zero and one. A value close to zero indicates a very connected network and a value of one means that every node is isolated (BORGATTI, 2006; SCHULZ et al., 2017).

\subsubsection{Loyalty and node-loyalty of the network}

We measured the proportion of preserved edges $(\theta)$ of a given premises between two consecutive years, $t-1$ and $t$, for the entire network. In order to quantify $\theta_{i}^{t-1, t}$, we define $Y_{i}^{t-1}$ as the set of edges from a premises $i$ in the time $t-1$ and $Y_{i}^{t}$ as the set of edges from a premises $i$ at time $t$. Then, $\theta_{i}^{t-1, t}$ is given by the Jaccard Index in equation 2 (VALDANO et al., 2015; SCHULZ et al., 2017).

$$
\overline{\text { edge loyalty }=\theta_{i}^{t-1, t}=\frac{\left|Y_{i}^{t-1} \bigcap \mathrm{Y}_{i}^{t}\right|}{\left|Y_{i}^{t-1} \cup \mathrm{Y}_{i}^{t}\right|} \backslash n \quad(2)}
$$

The Jaccard Index was also used to evaluate the proportion of premises that were active (moved at least one 
animal) in two consecutive periods for the hold network, which was divided by the total of premises in both considered times, following equation 3 .

$$
\overline{\nu \circ \delta \varepsilon \lambda \circ \psi \alpha \lambda \tau \psi=\varphi_{i}^{t-1, t}=\frac{\left|V^{t-1} \bigcap \mathrm{V}^{t}\right|}{\left|V^{t-1} \bigcup \mathrm{V}^{t}\right|} \backslash n \quad(3)}
$$

Where $V_{i}^{t-1}$ is the set of premises that are active in the period $t-1$, and $V_{i}^{t}$ is the set of premises that moved at least one animal at time $t$. For both analysis (loyalty and node-loyalty), we considered a span time $t$ of one year.

The yearly $\varphi_{i}^{t-1, t}$ and $\theta_{i}^{t-1, t}$ are expressed in a value between zero and one, where a $\theta_{i}^{t-1, t}$ of one indicates that $100 \%$ of links with same origin and destination were preserved (100\% loyalty between premises); and a value of one in $\varphi_{i}^{t-1, t}$ means that all premises were active in two consecutive periods, but not is necessarily trading with the same commercial partner.

\subsection{Time-windows network analysis}

A temporal network was considered, $g=(V, E, T)$, where $V$ is a set of nodes and $E$ a set of edges in each observation period $T$. Each edge in $E$ is given by a triple $(i, j, T)$ and connects node $i$ and node $j$ at time $T$. To describe the temporal patterns over time, we used a monthly time-window or series of snapshots, e.g. $g=g_{1}, \ldots, g_{\mathrm{T}} \cdot$ (HOLME; SARAMÄKI, 2012). The descriptive assessment of the temporal network snapshots was made with the same parameters described in the table 2.

\subsubsection{Causal fidelity}

Some paths existing between nodes in the static aggregation do not follow a chronological order, and therefore such paths do not exist in the temporal representation. To quantify the quality of a static aggregation, Lentz et al. (2013) defined so-called causal fidelity, which measures the proportion of paths in a temporal network which exist in the static counterpart. For this purpose, accessibility matrices are constructed for the static and temporal networks representing the path lengths between each pair of nodes. To calculate the causal fidelity of the network, it is necessary to calculate thepath density (equation 4), where we defined the density of its accessibility matrix:

$$
\overline{p\left(P_{n}\right)=\frac{\mathrm{nnz}\left(P_{n}\right)}{N^{2}} \quad(4)}
$$

where $P_{n}$ is the accessibility matrix for the path length $n=0, \ldots, N, \operatorname{nnz}\left(P_{n}\right)$ is the number of non-zero elements of the accessibility matrix, and $N$ is the number of nodes in the network. In the upper limit of path density, i.e. $p\left(P_{n}\right)=1$, most nodes can reach each other. On the contrary, for a low path density $p\left(P_{n}\right)=0$ the network tends to be temporarily disconnected ( Lentz et al., 2016)

Causal fidelity is calculated as the quotient of path densities, defined as:

$$
\begin{aligned}
& \mathbf{c}=\frac{p\left(P_{n}\right)}{p\left(\boldsymbol{\Omega}_{n}\right)}=\frac{\text { Number of paths in the temporal network }}{\text { Number of paths in the static network }} . \backslash n \quad(5) \\
& \hline
\end{aligned}
$$

The causal fidelity ranges between 0 [?] $c$ [?]1. Large values of $c$ indicate that the static aggregation of a temporal network gives a good approximation from a causal perspective and low values indicate that the majority of paths in the time-aggregated network are not in the right chronological order (Büttner et al., 2016; Lentz et al., 2016).

\subsubsection{Temporal network vulnerability and resilience}

The outgoing contact chain (OCC) quantifies the number of 'downstream' premises that could potentially acquire infection from the indexpremise through outgoing animal movements, adhering to the chronological 
order of the movements (FIELDING et al., 2019; PAYEN; TABOURIER; LATAPY, 2019).

We use this approach to build the OCC model, which can be viewed as a simplified representation a SI (susceptible- infected) model structure if every between-premise movement results in transmission; a potential outbreak can be seeded at a given time t0 in each node in turn, and the resulting OCC can be considered the outbreak size.

By simulating the OCC across all possible seed nodes, we generated a distribution of the network's OCC sizes. We then calculated the average OCC and 95\% CI across all premises using the entire period of study. We quantified the vulnerability of OCCs to the removal of 10, 250, 500, 1000 and 1500 nodes, with the order in which nodes were removed based on network metrics in descending order (Degree, Betweenness, Closeness, PageRank, OCC size), and also selecting Random-nodes. We then analyzed the changes in the mean OCC size over time.

\subsection{Network-based risk index}

SNA parameters values at the premise-level (Degree, Betweenness, Closeness and the reverse PageRank) were aggregated at the municipality level to visualize spatial hotspots of movement. As a network-based spatial risk index, we re-scaled all network metrics from zero to one, and then summed across all premises to generate the raw risk index and visualized a municipality-level risk map. To calculate the index, we summed the values for a specific SNA parameter (SNP) in the municipality as (eq. 6)

$$
\overline{S N P=\sum \Psi_{k} \quad(6)}
$$

Where $\Psi$ is the network parameter (indexed by $k$ premise) in a particular municipality $i$. The SNP was divided by the maximum value of all SNP within municipalities.

$$
\overline{\text { index }=\frac{\mathrm{SNP}_{i}}{\max (\mathrm{SNP})} \quad(7)}
$$

Therefore, using equation 7, a network-based risk index of one describes a municipality with the highest risk to receive infected animals by animal movements for the considered network.

Additionally, we also calculated a population-based index that standardized the raw index by the swine population reported for the last year of analysis in each municipality. We scaled the animal population size from zero to one, representing the proportion of animals in the municipality. In order to show the swine population at-risk related to the network-based risk index (equation 7), we scaled the index by swine population, following eq 8 ,

$\overline{\text { index pop }=\frac{\mathrm{SNP}_{i}}{\max (\mathrm{SNP})} * \frac{\sum S_{k}}{\max \left(\sum S_{k}\right)} \quad(8)}$

Where $\sum S_{k}$ represents the sum of swine population $S$ by premise $k$ in each municipality $i$. We present the results in two maps, the first showing only the raw index calculation and the second the index scaled by the total of swine population declared for the year 2017.

\subsection{Community detection}

In the state of SC, epidemiological surveillance and control units are organized at various levels starting at the municipality-level. For that reason, we aggregate the movements made by farms in each municipality, considering the municipality to be a node. This analysis captured spatial connectivity amongst different municipalities via animal movements, including pairs of locations that shared common direct and indirect connections within the network. Community detection was performed using an algorithm based on the calculation of LinkRank, a concept derived from Google's PageRank (BRIN; PAGE, 1998) that takes into 
account the incoming links of a given municipality and the incoming links of its neighbors (GRISI-FILHO et al., 2013).

We also calculated modularity as a measure of the strength of community structure, where values of 0.3 0.7 generally indicate moderate to strong community structure (GRANOVETTER, 1973).

All analysis and data visualization were performed in R statistical software (R CORE TEAM, 2017) version 2.4.2 using the packages: igraph version 1.1.2 (NEPUSZ, 2006), rgdal version 1.2-8 (KEITT et al., 2018), circlize version 0.4.1 (GU et al., 2014), EpiContactTrace version 0.12.0 (NÖREMARK; WIDGREN, 2014), tidyverse (Hadley Wickham, 2017), sf (PEBESMA, 2018), and the Illustrator CC5 software (GOLDING, 2017). Shapefiles to produce the maps were obtained from the Instituto Brasileiro de Geografia $e$ Estatística (www.ibge.gov.br).

\section{Results}

\section{Data}

The movements included in this study compromised $99.9 \%$ of the total available records. A small proportion of records were removed because the number of animals was listed as zero animals or $>20000$, which were considered errors. In this swine trade network, there were 11,606 premises, and 6,0645,853 pigs involved in 320,814 movements during the period of study.

\section{Data trade description}

Within SC, the dominant trade flow of animals originated from breeding-farms and CSBF and passed through Nurseries to Finisher farms. Finishers received a significant amount of movements from Nursery, Breeding and CSBF premises and, sent the largest flow of movements to Slaughterhouses.

We illustrated the main movements within and between types of premises in Figure 2; for visualization purposes, atypical movements representing less than $1 \%$ of the total of possible connections were excluded (Figure 2). The full description is available in the supplementary table 1.

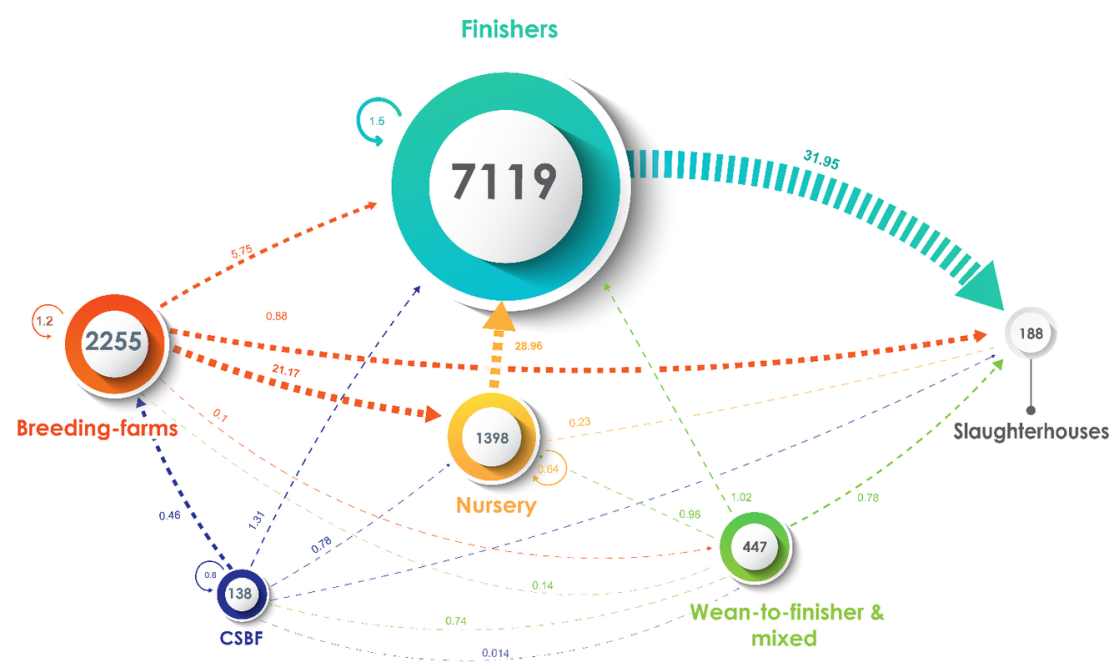

Figure 2 . Trade flow in SC state from 2015-01-01 and 2017-12-31. Arrows are weighted by the percentage of total movements and, the color indicates the origin of the movement. Circles represent the total of premises for each type of classification, and the size approximates the total of premises grouped by the circle.

\section{Static network and Fragmentation}


The yearly analysis of the static network showed a slight decrease through time for some metrics (number of nodes and edges, diameter, GSCC, Clustering coefficient and, GWCC) between 2015 and 2016 (Table 3). The GSCC represented just $6.41 \%$ of the total nodes for all years, and we found large differences in the size of the GSCC when we compared the annual networks and the overall network (aggregated across all years). The number of swine moved, graph density, and mean path length increased over time.

The full 2015-17 network had a fragmentation of 0.13 and GWCC of 0.93 , whereas the yearly snapshots networks were between 0.06 and 0.09 for fragmentation and 0.95 and 0.96 for the GWCC (Table 3). Taken together, these values indicate that the network exhibits a high degree of connectivity.

Table 3. Description of the annual static network and fragmentation values from 2015 to 2017, and for the overall network (2015-17) in the state of Santa Catarina, Brazil. The sizes of the components are presented in the number and percentage of total nodes in the network.

\begin{tabular}{|c|c|c|c|c|c|c|c|c|}
\hline Year & Nodes & Edges & $\begin{array}{l}\text { Graph } \\
\text { Density }\end{array}$ & $\begin{array}{l}\text { GSCC } \\
(\%)\end{array}$ & $\begin{array}{l}\text { GWCC } \\
(\%)\end{array}$ & Fragmentat & $\begin{array}{l}\text { Total } \\
\text { animals } \\
\text { inoved }\end{array}$ & $\begin{array}{l}\text { Mean } \\
\text { Path } \\
\text { length }\end{array}$ \\
\hline 2015 & 9,924 & 52,091 & 0.000529 & $\begin{array}{l}21 \\
(0.21 \%)\end{array}$ & $\begin{array}{l}9463 \\
(95 \%)\end{array}$ & 0.09 & $18,955,998$ & 2.90 \\
\hline 2016 & 9,598 & 51,402 & 0.000559 & $\begin{array}{l}65 \\
(0.68 \%)\end{array}$ & $\begin{array}{l}9191 \\
(95 \%)\end{array}$ & 0.08 & $20,364,474$ & 5.16 \\
\hline 2017 & 9,218 & 46,604 & 0.000549 & $\begin{array}{l}22 \\
(0.23 \%)\end{array}$ & $\begin{array}{l}8894 \\
(96 \%)\end{array}$ & 0.06 & $21,249,869$ & 5.83 \\
\hline $\begin{array}{l}\text { All } \\
\text { Years }\end{array}$ & 11,616 & 112,402 & 0.000835 & $\begin{array}{l}744 \\
(6.4 \%)\end{array}$ & $\begin{array}{l}10820 \\
(93 \%)\end{array}$ & 0.13 & $60,570,341$ & 7.18 \\
\hline
\end{tabular}

At the premises level, in-degree showed a wider distribution than out-degree, with more premises having three to ten unique trading partners (Figure 3a). A visual examination of the distribution of the number of animals moved per premise according to the purpose of the movement showed a correlation between slaughterhouse and reproduction purposes (Figure 3b).

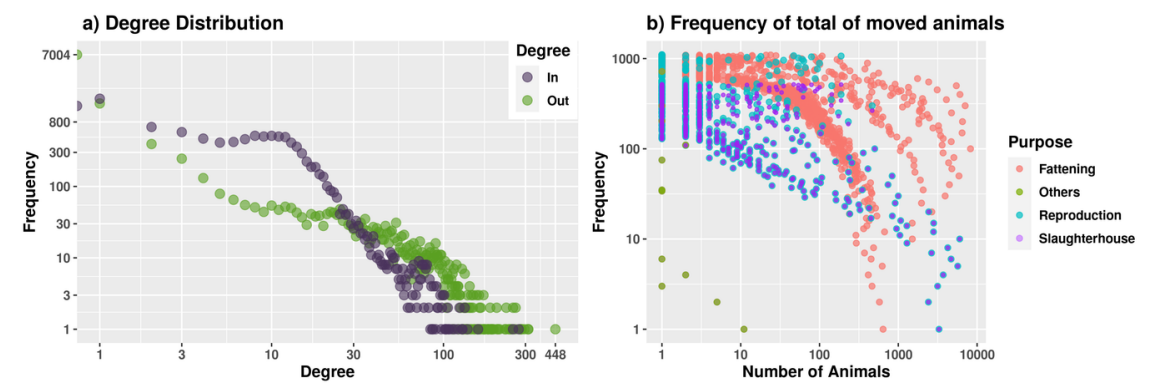

Figure 3 . a) Distribution of in- and out-degree for all premises. b) Distribution of the number of animals moved per premises. Both axes are on a base10 logarithmic scale in both panels.

Edge-loyalty $(\theta)$ and node-loyalty $(\varphi)$ of the network

The union and intersection of the edges and nodes were calculated between consecutive years. Loyalty was far lower from 2016-17 than from 2015-16, even though more than 79\% of nodes remained active across the years (Table 4 ).

Table 4. The proportion of intersection and union and loyalty values from edges and nodes. 


\begin{tabular}{lllllll}
\hline Period of time & Union of edges & Intersection of edges & Edge-Loyalty $(\vartheta)$ & Union of nodes & Intersection of nodes & Node \\
\hline $2015-2016$ & 85,833 & 51,403 & 0.59 & 10877 & 9594 & 0.88 \\
$2016-2017$ & 81,721 & 16,287 & 0.19 & 10487 & 8319 & 0.79 \\
\hline
\end{tabular}

\section{Temporal network}

We assessed the temporal network in monthly snapshots, describing the patterns of the pig trade throughout the period of study using the parameters described in table 2 .

The number of nodes and edges decreased over time, ranging between 3548 to 4157 and 7849 to 9979 , respectively. The mean and sum of pigs moved per movement increased over time. The percentage of the GSCC and GWCC varied through time without an apparent temporal trend. Graph density, clustering coefficient, and in-degree centralization showed a peak value in the middle of the year 2016 (figure 4).

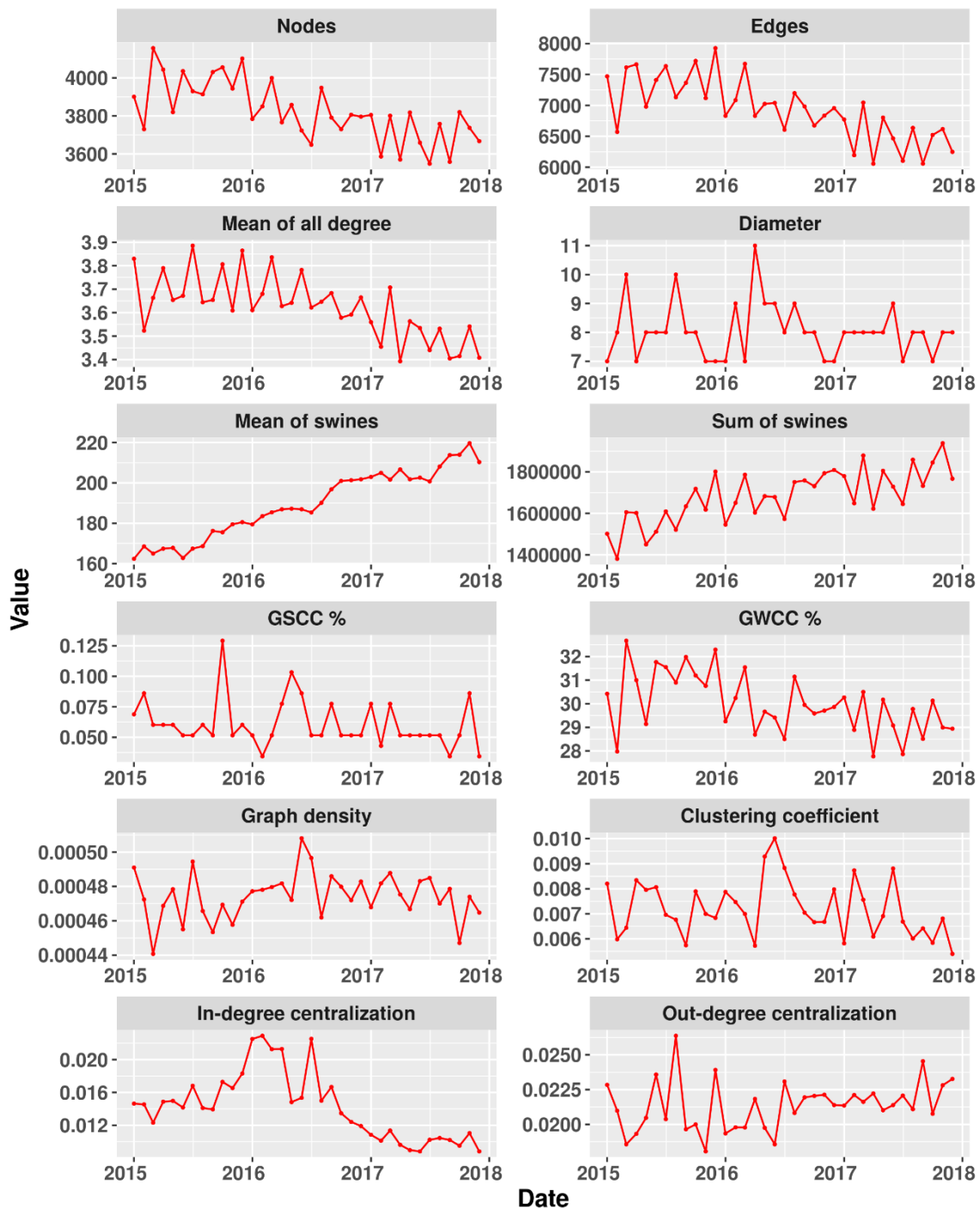

Figure 4 . Description of the temporal network using a monthly time- snapshots network by network-level 
metrics; more details about the metrics are shown in supplementary table 1.

\subsubsection{Causal fidelity}

For the whole observation period, 11,226,066 paths were observed in the static network but only 1,287,009 time-respecting paths in the temporal network could be obtained, which results in a causal fidelity of 0.11 . Thus, about $11 \%$ of the time-respecting paths exist in both network representations, indicating that the static representation of the network poorly captured the features of the temporal network.

\subsubsection{Temporal network vulnerability and resilience}

The size of the OCC (outgoing contact chain) was calculated for all nodes. In general, the removal of nodes based on degree, betweenness, and reverse PageRank resulted in greater decreases in the OCC sizes as compared to the removal of nodes based on PageRank or at random (Figure 5). The removal of only 10 nodes had a little impact regardless of how the removed nodes were selected. However, targeted removal of $>250$ highly connected nodes resulted in a noticeable decrease in OCC. Removal of just 250 nodes $(2.15 \%$ of the total network) led to up to a $50 \%$ decrease in mean OCC when using degree as the targeting metric. The complete distribution values for each SNA parameter after each node removal were plotted (supplementary figure 1), and for visualization, the mean and confidence intervals are shown by week (Figure 5).

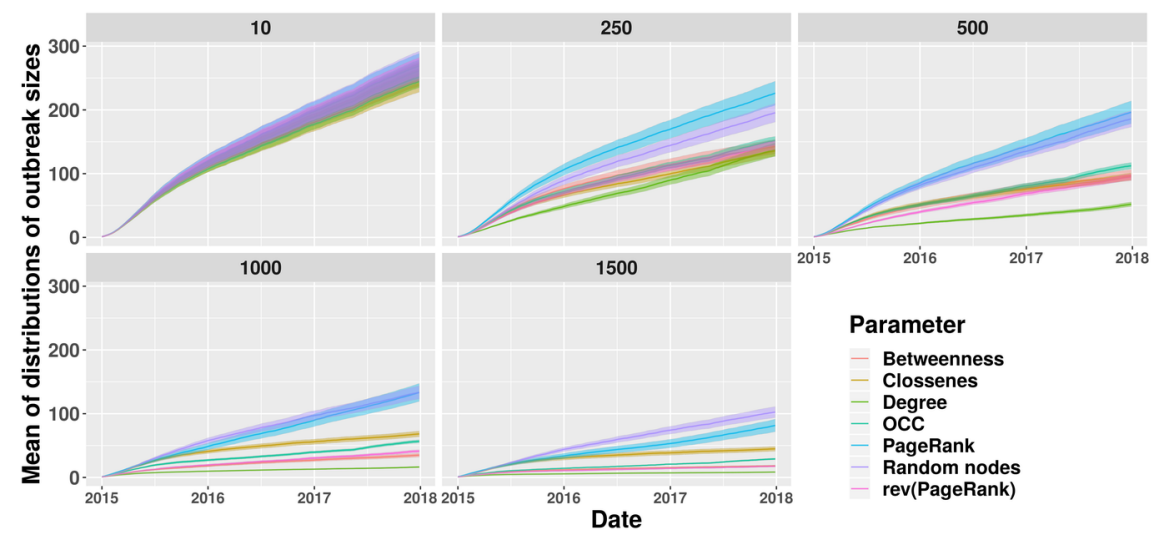

Figure 5. Temporal network vulnerability. Each line represents the average of the size of the outgoing contact chain (OCC) through time after removal of the top 10, 250, 500, 750 and 1000 nodes ranked according to various network parameters. The colored shaded areas represent confidence interval (CI 95\%).

Figure 6 shows the frequencies of OCCs resulting from the removal of $10-1500$ nodes. When 1500 nodes were removed, selection of nodes based on degree resulted in a lower OCC sizes distribution, followed by reverse PageRank and betweenness. 


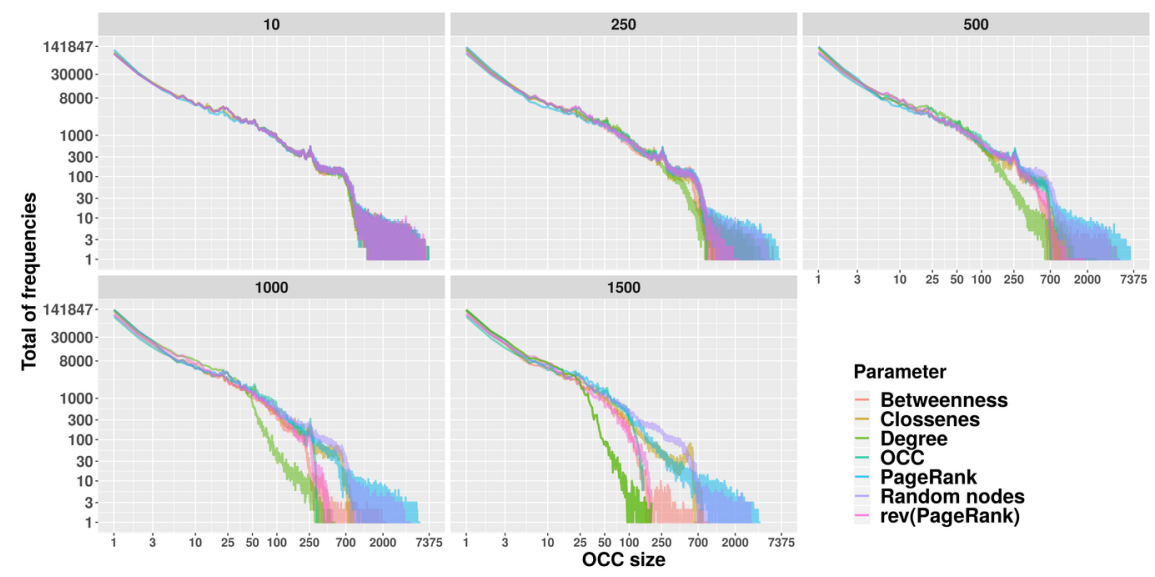

Figure 6. Mined data of frequencies of OCCs resulting from the node after removal of the top 10, 250, 500, 750 and 1000 nodes ranked according to various network parameters. Each line color represents a SNA parameter.

\section{Network-based risk index}

From the above analysis, we can discriminate the parameters that best capture the temporal network's vulnerability and resilience. Thus, we selected the parameters that resulted in the greatest reduction in OCC (Degree, Betweenness, Closeness, and reverse PageRank) for our network-based risk index and index pop. These indexes were calculated to quantify spatial patterns and identify municipalities that were hotspots for movement. The network-based results, either raw or standardized for swine population size, are shown in Figures 7 and 8, respectively. The municipalities that played a key role in the pig trade network in SC state for both maps were Concórdia, Seara, and Videira.

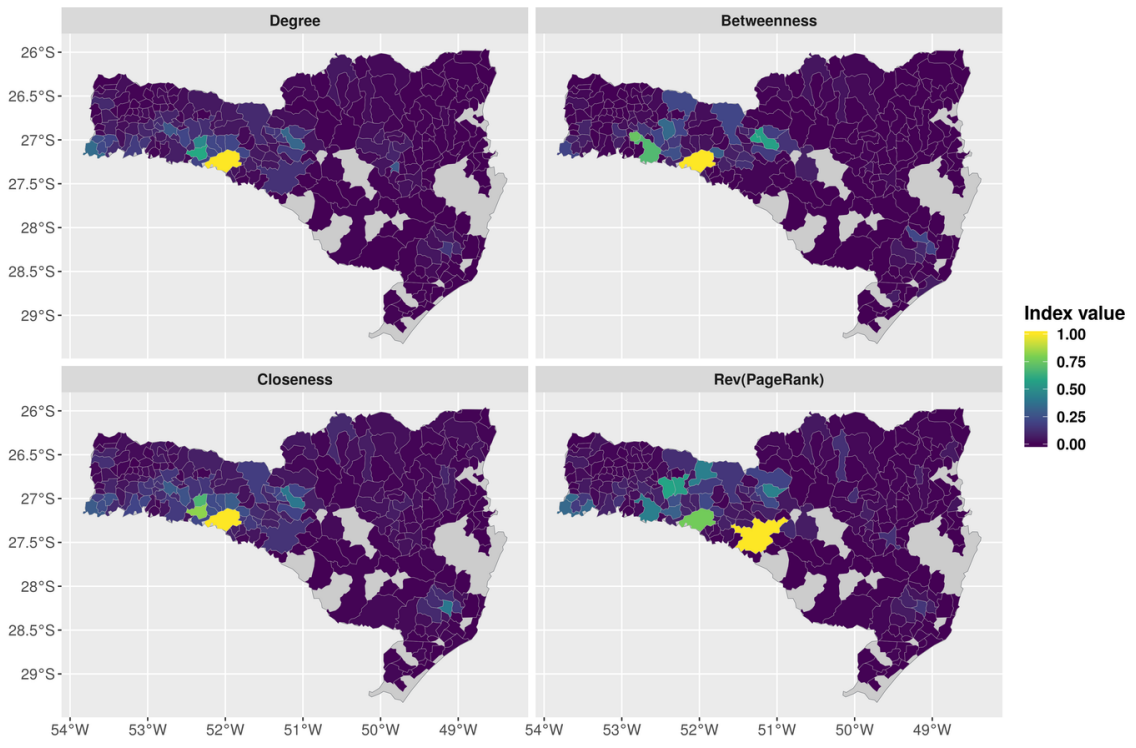

Figure 7. Map of the network-based risk index by municipality from SC State, Brazil. The maps are faceted by SNA parameter (Degree, Betweenness, Closeness and finally Rev(PageRank)). 


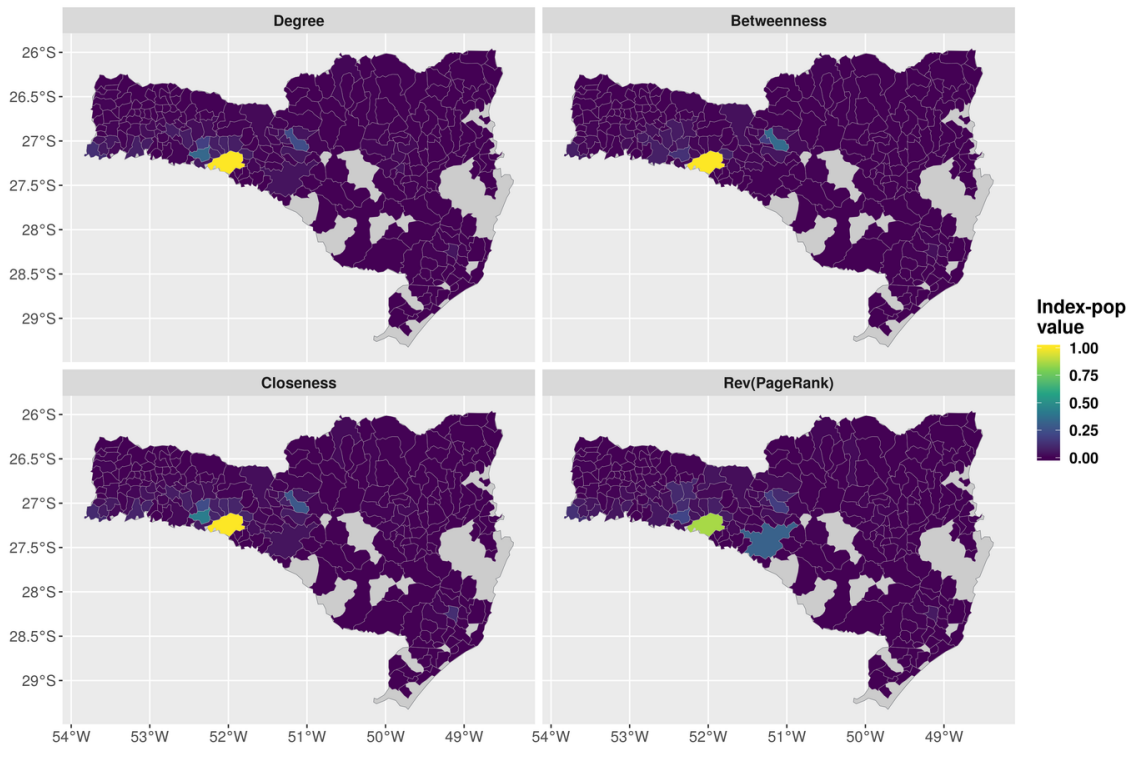

Figure 8. Map of the Network-based riskindex pop here was considered the swine population in each municipality from SC, Brazil. The maps are faceted by SNA parameter (Degree, Betweenness, Closeness and finally $\operatorname{Rev}($ PageRank)).

\section{Communities}

Communities are sets of nodes (municipalities in this case) that interact more frequently with one another than with nodes from other communities. The spatial distribution and the proportion of the movements within communities are shown in figure 9 . The modularity value was 0.35 , indicating a moderate community division. As shown in figure 1, there are no premises located in certain municipalities and therefore they could not be assigned to a specific community (NA in figure $9 \mathrm{~b}$ ). 

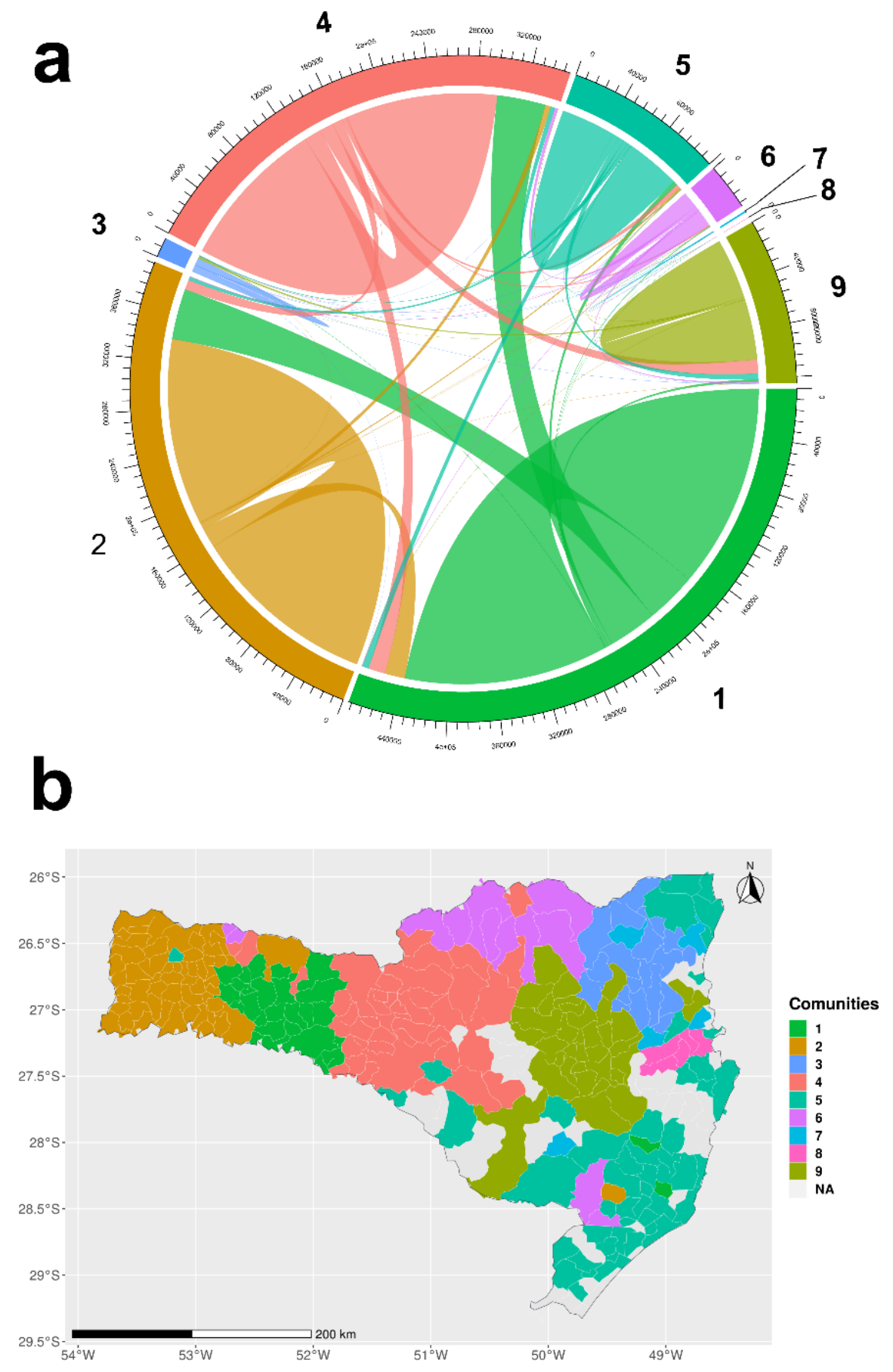

Figure 9. Spatial and structural characterization of the largest trade communities. Color indicates the community membership. a) Circular plot for intra- and inter-community movement flows. Each sector of the circle represents a community. The outgoing animal flow starts from the base of each sector. (b) Map of the state of Santa Catarina, Brazil with the geographical locations of the communities by the municipality. NA represents municipalities without reported movements.

\section{Discussion}


In this research, we use a two-pronged approach (static and temporal) network analysis aimed at exploring and characterizing pig trade at global and node levels in Santa Catarina, Brazil. We also propose a methodology for ranking high-risk areas for enhancing control and surveillance in communicable diseases considering the dynamics of swine trade. We used a static network analysis approach to describe the general structure of the network (Table 3 and Fig. 2) and temporal analysis to describe the dynamic trends using monthly snapshots (Fig. 4). Since we found a low value of causal fidelity, we used the OCC approach that considers time-respecting paths to analyze the vulnerability of the network to targeted node removal (Fig. 5 and Fig 6.). To understand the spatial distribution of risk, we calculated a risk index to prioritize the control and surveillance actions at the municipality level (Fig. 7 and Fig. 8) and performed a community analysis to describe the flux of movements between municipalities (Fig. 9).

In the static network analysis, the results of our loyalty analysis (nodes and edges) suggest that the commercial relationships from one year to another were not highly conserved despite the fact that a large portion of the nodes were active in both periods of time. There was also a drastic decrease in edge loyalty from 0.59 to 0.19 across the two periods observed. In addition, the proportion of nodes that remained active from year-to-year fell from 0.88 to 0.79 . These patterns could exacerbate the potential for the spread of infectious diseases because many connections over time are not predictable.

The observed degree distributions showed scale-free properties, with many premises trading animals with only a few direct partners and a small number of premises trading with many direct partners. Above a value of 30, high out-degree premises were more common than high in-degree premises (Fig. 3). This is mainly given by the degree distribution of Breeding-farms and Nursery-farms (supplementary Fig. 2), reflecting vertical integration of production chains. The pyramidal structure of the production chain also may explain the low sizes of GSCCs, whereas GWCCs showed high levels of connectivity, compromising more than $95 \%$ of the network (table 4).

In the analysis of temporal trends, we found a decreasing number of active nodes and edges but an increasing number of swine moving throughout the study (Fig. 4). These findings suggest an increase in the size of premises and number of animals mobilized. Similar trends also were observed in other Brazilian state, and Swedish and Danish pig trade, (NÖREMARK et al., 2011; SCHULZ et al., 2017; STERCHI et al., 2019; MACHADO et al., 2020). Moreover, monthly values for the clustering coefficient and graph density were similar to mid-range values reported in other livestock networks (NÖREMARK et al., 2011; MWEU et al., 2013; VANDERWAAL et al., 2016b; FIELDING et al., 2019). We could not detect clear seasonal activity patterns as observed in others pig trade networks (KONSCHAKE et al., 2013; BÜTTNER; SALAU; KRIETER, 2016).

Given that static networks are more straight-forward to analyze, it is essential to understand the fidelity of the static network in representing a temporally dynamic network. To answer this, we followed the methodology proposed by Lentz et al., and demonstrated a low causal fidelity value. This indicates that the static networks may lead to an over-representation of the true connectivity of the network (LENTZ; SELHORST; SOKOLOV, 2013; LEBL et al., 2016), and thus inappropriate assessments of risk or design of control strategies. If the disease dynamics are slow in relation to the dynamics of the network, the results of the static network analysis may be sufficient to explain and predict a possible disease transmission (HOLME; SARAMÄKI, 2012). However, the use of a static representation for disease models may systematically overestimate the results of outbreak size, particularly for rapidly spreading diseases (LENTZ; SELHORST; SOKOLOV, 2013; KNIFIC et al., 2020).

Therefore, the use of temporal OCC analyses provides a better approach to evaluate the impact of target control because it incorporates the chronological nature of animal movements. The literature on temporal network analysis uses many terms to describe the OCC concept, such as time-directed paths, source counts, accessible worlds, output domains, reachability, unfolding accessibility, and recently spreading cascades (PAYEN; TABOURIER; LATAPY, 2019; KNIFIC et al., 2020). All of these terms describe a temporally sequential network to identify the nodes that are accessible through edges to/from each index node within a selected time period (FIELDING et al., 2019). We selected the term OCC to describe the number of nodes 
that could be reached from a certain premise, and this process represents a simple Susceptible-Infected (SI) model assuming a $100 \%$ infection rate via animal movements using the time-respecting paths. Thus, testing targeted control actions under this scenario provides useful information for field performance (VIDONDO; VOELKL, 2018; PAYEN; TABOURIER; LATAPY, 2019).

The most common strategies to contain an epidemic outbreak include culling, isolation of holdings, increased hygiene measures, and vaccination, among others (MOTTA et al., 2017). Targeting these measures towards premises with high centrality can be an effective strategy for efficient disease control. Analysis of the impact of targeted node removal on network connectivity generally measure the impact of removals on the size of the GWCC and GSCC (BÜTTNER et al., 2013; LENTZ et al., 2016; MARQUETOUX et al., 2016; MOTTA et al., 2017; CHATERS et al., 2019), which does not account for temporal dynamics. For this reason, we used reductions in the mean size of OCC to measure the efficacy of targeted removals, thus accounting for time-respecting paths.

Based on this analysis, we showed that prioritizing the removal of farms based on degree substantially reduced the potential for transmission of an infectious pathogen in the contact network as compared to removing farms at random. Therefore, control actions should be focused on high degree farms, such as Nursery and Breeding-farms (see supplementary Fig 2). In our study, a $>90 \%$ decrease in the mean OCC mean was achieved by removing just 1000 nodes, which is particularly important in surveillance and control systems with limited resources.

We proposed a network-based index classification to target surveillance actions and assist surveillance authorities to classify areas (municipalities) according to the probability and consequence of certain areas becoming infected via in/out movements. The selection of the metrics to compose the indexes was based on the network metrics that were most effective at reducing the size of the OCC (Degree, Betweenness, Closeness) and the reverse of PageRank). Hence, we identified nodes at the beginning of the contact chain that traded with hubs of the network that, in theory, might be the beginning of the production chain and therefore have an important role in the disease spreading. Based on these, we implemented the Reverse of PageRank as network metric, due these nodes that can induce bigger changes in the mean OCC after node removal.

We also standardized these indexes according to the swine population of each region, thus creating a visualization of the most important regions which could be prioritized for control actions. These geographical areas were highly correlated with farm density (Figs. 1 and 8), which was one of the motivations to carry out the community analysis.

We found 9 large trade communities in SC State. Communities 1,2 and 4 were geographically connected and registered the $60.8 \%$ of animal movements. Inter-community trade flux represented just $23.6 \%$ of movements, and most main flows were from community 1 to communities 2 and $4(11.1 \%)$. The main purposes for the latter were slaughter $(8.17 \%)$, fattening $(2.28 \%)$ and reproduction $(0.64 \%)$, thus the southwest region of SC state is the most important for swine trade based on both high internal trade and density of premises (See figure 1 and 9). The use of communities offers the opportunity to control outbreaks through zonation or compartmentalization by sub-dividing the state into sectors in which movements are more frequent within sectors than between sectors (OIE, 2019). Thus, if one sector were to become infected, trade in other sectors could potentially be protected via coordination of inter- and intra-sector disease management strategies (CHRISTLEY et al., 2005; LENTZ et al., 2011; GRISI-FILHO et al., 2013; GORSICH et al., 2016).

Animal movements are just one aspect of the epidemiology of infectious diseases. Despite the importance of movements (O'HARA et al., 2020; VANDERWAAL et al., 2020) network analysis should be undertaken in conjunction with other epidemiological tools. Several limitations of our work include that we were not able to include the effects of illegal movements and their influence on the network. We also could not rule out the possibility that an animal diseases outbreak could affect the dynamics of the network. This study also assumes that transmission of diseases related to the outgoing contact chain spread only via animal movements and that each movement is successful in disease transmission, which likely results in an overestimate of OCC 
size. Furthermore, we inherently neglected other potential transmission pathways such as movement of other susceptible or non-susceptible animal species, movement of owners, workers or veterinarians, transmission via vehicles, shared equipment or bioaerosols (KNIFIC et al., 2020), etc., which may have resulted in an under-approximation of the worst-case scenario for the introduction and spread of an exotic animal disease.

\section{Conclusion}

The network analysis and indexes presented here provide useful data to rank premises and guide the development of targeted surveillance and control schemes. We documented temporal and spatial patterns of trade, and outline how this temporal and spatial variation could be used to design data-informed strategies for disease surveillance and control.

\section{Acknowledgment}

This study was financed in part by the Coordenação de Aperfeiçoamento de Pessoal de Nível Superior Brasil (CAPES) - Finance Code 001.

Acknowledgments for Ministério Agricultura, Pecuária e Abastecimento (MAPA), and Companhia Integrada de Desenvolvimento Agrícola de Santa Catarina (CIDASC)

\section{References}

BAJARDI, P. et al. Optimizing surveillance for livestock disease spreading through animal movements. Journal of The Royal Society Interface, v. 9, n. 76, p. 2814-2825, 7 nov. 2012. Disponível em: <http://rsif.royalsocietypublishing.org/content/early/2012/06/21/rsif.2012.0289.abstract>.

BORGATTI, S. P. Identifying sets of key players in a social network.Computational and Mathematical Organization Theory, v. 12, n. 1, p. 21-34, abr. 2006. Disponível em: <https://doi.org/10.1007/s10588006-7084-x>.

BRIN, S.; PAGE, L. The anatomy of a large-scale hypertextual Web search engine. Computer Networks and ISDN Systems , v. 30, n. 1-7, p. 107-117, abr. 1998. Disponível em: $<$ http://dx.doi.org/10.1016/S0169-7552(98)00110-X>.

BÜTTNER, K. et al. Efficient Interruption of Infection Chains by Targeted Removal of Central Holdings in an Animal Trade Network.PLoS ONE , v. 8, n. 9, p. e74292, 2013. Disponível em: <https://doi.org/10.1371/journal.pone.0074292>.

BÜTTNER, K.; SALAU, J.; KRIETER, J. Quality assessment of static aggregation compared to the temporal approach based on a pig trade network in Northern Germany. Preventive Veterinary Medicine , v. 129, p. 1-8, jul. 2016. Disponível em: <http://www.sciencedirect.com/science/article/pii/S0167587716301350>.

CHATERS, G. L. et al. Analysing livestock network data for infectious disease control: an argument for routine data collection in emerging economies. Philosophical Transactions of the Royal Society B: Biological Sciences , v. 374, n. 1776, p. 20180264, 8 jul. 2019. Disponível em: <https://doi.org/10.1098/rstb.2018.0264>.

CHRISTLEY, R. M. et al. Infection in Social Networks: Using Network Analysis to Identify High-Risk Individuals. American Journal of Epidemiology , v. 162, n. 10, p. 1024-1031, 15 nov. 2005. Disponível em: <http://www.ncbi.nlm.nih.gov/pubmed/16177140>.

EMBRAPA. Empresa Brasileira de Pesquisa Agropecuária . Disponível em: <https://www.embrapa.br/suinos-e-aves/cias/estatisticas/suinos/brasil >. Acesso em: 3 jul. 2019.

FIELDING, H. R. et al. Contact chains of cattle farms in Great Britain.Royal Society Open Science , v. 6, n. 2, p. 180719, 28 fev. 2019. Disponível em: < doi.org/10.1098/rsos.180719>. 
FREEMAN, L. C. Centrality in social networks conceptual clarification.Social Networks, v. 1, n. 3, p. 215-239, jan. 1978. Disponível em: <http://www.sciencedirect.com/science/article/pii/0378873378900217>.

GOLDING, with M. Adobe Illustrator CS5 : for web and interactive design Ventura, CA : Lynda.com, [2010] (c)2010, , 2017. . Disponivel em: $<$ https://search.library.wisc.edu/catalog/9910101663502121>.

GORSICH, E. E. et al. Mapping U.S. cattle shipment networks: Spatial and temporal patterns of trade communities from 2009 to 2011.Preventive Veterinary Medicine, v. 134, n. Supplement C, p. 82-91, nov. 2016. Disponivel em: <http://www.sciencedirect.com/science/article/pii/S016758771630410X>.

GRANOVEtTeR, M. S. The Strength of Weak Ties. American Journal of Sociology, v. 78, n. 6, p. 1360-1380, 1973. Disponivel em: < http://www.jstor.org/stable/2776392>.

GRISI-FILHO, J. H. H. et al. Detecting livestock production zones.Preventive Veterinary Medicine , v. 110, n. 3-4, p. 304-311, 1 jul. $2013 . \quad$ Disponivel em: $<$ http://www.sciencedirect.com/science/article/pii/S0167587713000044>.

GU, Z. et al. circlize implements and enhances circular visualization in R. Bioinformatics , v. 30, n. 19, p. 2811-2812, 1 out. 2014. Disponivel em: <http://dx.doi.org/10.1093/bioinformatics/btu393>.

HOLME, P.; SARAMAKI, J. Temporal networks. Physics Reports, v. 519, n. 3, p. 97-125, out. 2012. Disponivel em: <https://linkinghub.elsevier.com/retrieve/pii/S0370157312000841>.

KEITT, T. et al. rgdal: Bindings for the Geospatial Data Abstraction Library, 1 jan. 2018. . Disponivel em: <https://cran.r-project.org/package=rgdal $>$.

KNIFIC, T. et al. Implications of Cattle Trade for the Spread and Control of Infectious Diseases in Slovenia Frontiers in Veterinary Science , 2020. . Disponivel em: $<$ https://www.frontiersin.org/article/10.3389/fvets.2019.00454>.

KONSCHAKE, M. et al. On the Robustness of In- and Out-Components in a Temporal Network. PLoS ONE, v. 8, n. 2, p. e55223, 6 fev. 2013. Disponivel em: $<$ https://dx.plos.org/10.1371/journal.pone.0055223>.

LEBL, K. et al. Impact of Network Activity on the Spread of Infectious Diseases through the German Pig Trade Network. Frontiers in Veterinary Science, v. 3, n. June, p. 48, 2016. Disponivel em: $<$ http://journal.frontiersin.org/Article/10.3389/fvets.2016.00048/abstract>.

LENTZ, H. H. K. et al. Trade communities and their spatial patterns in the German pork production network. Preventive Veterinary Medicine, v. 98, n. 2-3, p. 176-181, fev. 2011. Disponivel em: $<$ http://www.sciencedirect.com/science/article/pii/S0167587710002965>.

LENTZ, H. H. K. et al. Disease Spread through Animal Movements: A Static and Temporal Network Analysis of Pig Trade in Germany. PLoS ONE , v. 11, n. 5, p. e0155196, 6 maio 2016. Disponivel em: $<$ http://dx.doi.org/10.1371\%2Fjournal.pone.0155196>.

LENTZ, H. H. K.; SELHORST, T.; SOKOLOV, I. M. Unfolding Accessibility Provides a Macroscopic Approach to Temporal Networks. Physical Review Letters , v. 110, n. 11, p. 118701, 11 mar. 2013. Disponivel em: <https://link.aps.org/doi/10.1103/PhysRevLett.110.118701>.

MACHADO, G. et al. Quantifying the dynamics of pig movements improves targeted disease surveillance and control plans. Transboundary and Emerging Diseases, p. tbed.13841, 4 out. 2020. Disponivel em: <https://onlinelibrary.wiley.com/doi/10.1111/tbed.13841>.

MAPA. Caracterizacao dos sistemas produtivos brasileiros . Disponivel em: $<$ http://www.agricultura.gov.br/assuntos/sanidade-animal-e-vegetal/saude-animal/programas-de-saudeanimal/febre-aftosa/pnefa-2017-2026/arquivos/4_analise_distribuicao-espacial_usp_2.pdf $>$. Acesso em: 13 jul. 2018. 
MARQUETOUX, N. et al. Using social network analysis to inform disease control interventions. Preventive Veterinary Medicine , v. 126, p. 94-104, abr. 2016. Disponivel em: $<$ https://linkinghub.elsevier.com/retrieve/pii/S0167587716300393>.

MOSLONKA-LEFEBVRE, M. et al. Market analyses of livestock trade networks to inform the prevention of joint economic and epidemiological risks.Journal of the Royal Society Interface , v. 13, n. 116, p. 20151099, 22 mar. 2016. Disponivel em: <http://www.ncbi.nlm.nih.gov/pmc/articles/PMC4843675/>.

MOTTA, P. et al. Implications of the cattle trade network in Cameroon for regional disease prevention and control. Scientific Reports , v. 7, n. 1, p. 43932, 7 abr. 2017. Disponivel em: $<$ http://dx.doi.org/10.1038/srep43932>.

MWEU, M. M. et al. Temporal characterisation of the network of Danish cattle movements and its implication for disease control: 2000-2009.Preventive Veterinary Medicine, v. 110, n. 3-4, p. 379-387, jul. 2013. Disponivel em: <http://www.sciencedirect.com/science/article/pii/S0167587713000640>.

NEPUSZ, G. C. and T. The igraph software package for complex network research. InterJournal , v. Complex Sy, p. 1695, 2006. Disponivel em: <http://igraph.org >.

NOREMARK, M. et al. Network analysis of cattle and pig movements in Sweden: Measures relevant for disease control and risk based surveillance. Preventive Veterinary Medicine , v. 99, n. 2, p. 78-90, 2011. Disponivel em: <http://www.sciencedirect.com/science/article/pii/S0167587711000043>.

NOREMARK, M.; WIDGREN, S. EpiContactTrace: an R-package for contact tracing during livestock disease outbreaks and for risk-based surveillance. BMC Veterinary Research , v. 10, n. 1, p. 71, 2014. Disponivel em: < https://doi.org/10.1186/1746-6148-10-71>.

O'HARA, K. et al. Network Analysis of Swine Shipments in China: The First Step to Inform Disease Surveillance and Risk Mitigation Strategies. Frontiers in Veterinary Science, v. 7, p. 189, abr. 2020.

OIE. Terrestrial Animal Health Code .

PAYEN, A.; TABOURIER, L.; LATAPY, M. Spreading dynamics in a cattle trade network: Size, speed, typical profile and consequences on epidemic control strategies. PLOS ONE , v. 14, n. 6, p. e0217972, 10 jun. 2019. Disponivel em: < https://doi.org/10.1371/journal.pone.0217972>.

PEBESMA, E. Simple Features for R: Standardized Support for Spatial Vector Data. The R Journal , v. 10, n. 1, p. 439, 2018. Disponivel em: < https://journal.r-project.org/archive/2018/RJ-2018009/index.html>.

R CORE TEAM. R: A language and environment for statistical computing Vienna, Austria, AustriaR fundation for Statistical Computing, , 2017. . Disponivel em: <https://www.r-project.org $>$.

SCHULZ, J. et al. Network analysis of pig movements: Loyalty patterns and contact chains of different holding types in Denmark. PLOS ONE , v. 12, n. 6, p. e0179915, 29 jun. 2017. Disponivel em: $<$ https://doi.org/10.1371/journal.pone.0179915>.

STERCHI, M. et al. The pig transport network in Switzerland: Structure, patterns, and implications for the transmission of infectious diseases between animal holdings. PLOS ONE , v. 14, n. 5, p. e0217974, 31 maio 2019. Disponivel em: <https://doi.org/10.1371/journal.pone.0217974>.

VALDANO, E. et al. Predicting Epidemic Risk from Past Temporal Contact Data. PLOS Computational Biology, v. 11, n. 3, p. e1004152, 12 mar. 2015. Disponivel em: $<$ https://doi.org/10.1371/journal.pcbi.1004152>.

VANDERWAAL, K. et al. Evaluating empirical contact networks as potential transmission pathways for infectious diseases. Journal of The Royal Society Interface, v. 13, n. 121, p. 20160166, 3 ago. 2016a. Disponivel em: <http://rsif.royalsocietypublishing.org/lookup/doi/10.1098/rsif.2016.0166>. 
VANDERWAAL, K. et al. Contrasting animal movement and spatial connectivity networks in shaping transmission pathways of a genetically diverse virus. Preventive Veterinary Medicine, v. 178, p. 104977, maio 2020.

VANDERWAAL, K. L. et al. Network analysis of cattle movements in Uruguay: Quantifying heterogeneity for risk-based disease surveillance and control. Preventive Veterinary Medicine, v. 123, p. 12-22, 1 jan. 2016b. Disponivel em: <http://www.sciencedirect.com/science/article/pii/S0167587715300945>.

VIDONDO, B.; VOELKL, B. Dynamic network measures reveal the impact of cattle markets and alpine summering on the risk of epidemic outbreaks in the Swiss cattle population. BMC Veterinary Research , v. 14, n. 1, p. 88, 13 dez. 2018. Disponivel em: <https://doi.org/10.1186/s12917-018-1406-3>.

WASSERMAN, S.; FAUST, K. Social Network Analysis: Methods and Applications . [s.l.] Cambridge University Press, 1994.

WATTS, D. J.; STROGATZ, S. H. Collective dynamics of 'small-world' networks. Nature, v. 393, n. 6684, p. 440-442, jun. 1998. Disponivel em: < https://doi.org/10.1038/30918>.

\section{Supplementary material}

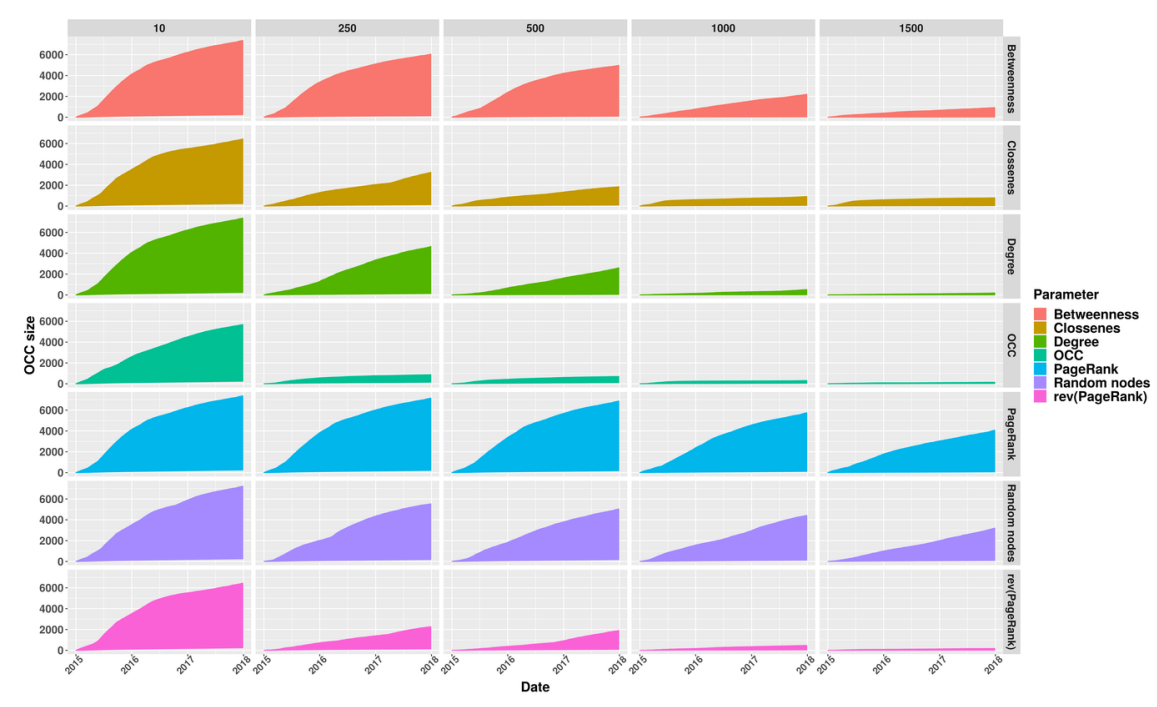

Supplementary Figure 1. Each line represents the average of the outgoing contact chain after remove 10, 250, 500, 750 and 1000 nodes ranked by the higher values network parameter. The colored shaded areas of the lines represent the maximum and minimum values over all study period. 


\section{a}
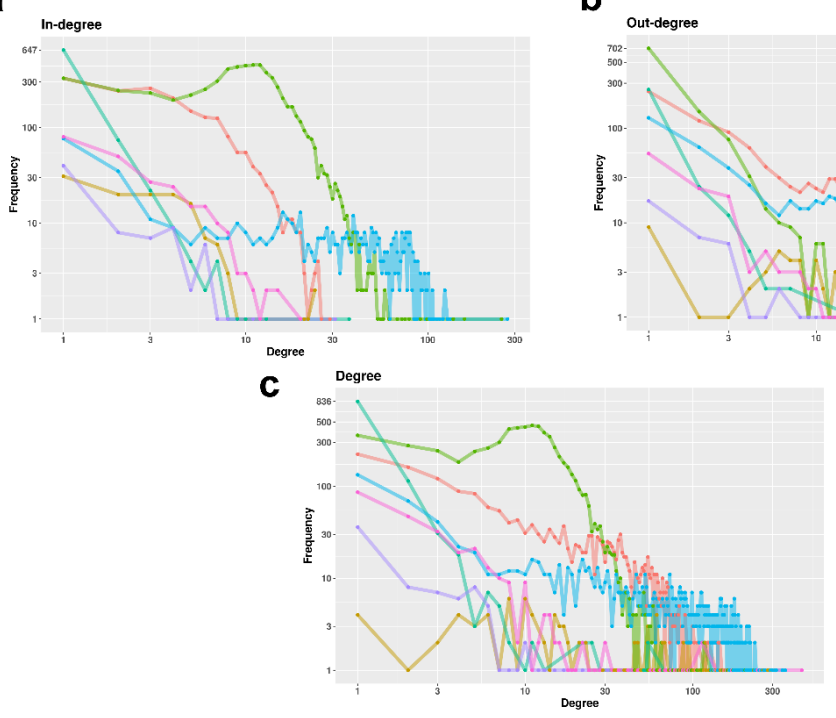

b

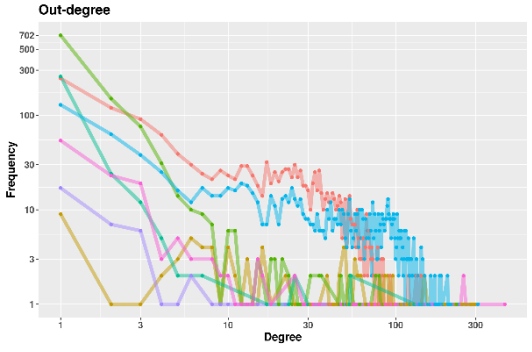

Type of premise

- Breeding-farm
- Certified-Swine-Breeder-Farm

- Finisher

Non-Comercial

Nursery

Wean-to-finisher \& mixed

Supplementary Figure 2. Degree distribution by type of premises in SC, stated from 2015-2018. The space breaks between the numbers in the $\mathrm{x}$ and $\mathrm{y}$ axis are on a base10 logarithmic scale. a) In-degree degree distribution of premises, b) out-degree distribution of premises, c) Degree or all degree distribution of the premises.

Supplementary table 1. Number and proportion of animals and movements within types of premises in SC state from 2015 to 2017

\begin{tabular}{llllll}
\hline Origin & Destination & movements & Animals & mov. percentage & Ani. pe \\
\hline Finisher & Slaughterhouse & 332446 & 29596902 & 43,97 & 31,951 \\
Nursery & Finisher & 116052 & 26831783 & 15,349 & 28,966 \\
Breeding-farm & Nursery & 77192 & 19619039 & 10,21 & 21,179 \\
Breeding-farm & Slaughterhouse & 64277 & 815985 & 8,501 & 0,881 \\
Certified-Swine-Breeder-Farm & Breeding-farm & 35391 & 430150 & 4,681 & 0,464 \\
Breeding-farm & Finisher & 28357 & 5327584 & 3,751 & 5,751 \\
Wean-to-finisher \& mixed & Slaughterhouse & 16897 & 726551 & 2,235 & 0,784 \\
Wean-to-finisher \& mixed & Breeding-farm & 13241 & 137096 & 1,751 & 0,148 \\
Certified-Swine-Breeder-Farm & Slaughterhouse & 10780 & 565621 & 1,426 & 0,611 \\
Finisher & Finisher & 8184 & 1410404 & 1,082 & 1,523 \\
Certified-Swine-Breeder-Farm & Certified-Swine-Breeder-Farm & 6078 & 1139240 & 0,804 & 1,23 \\
Nursery & Slaughterhouse & 5990 & 214461 & 0,792 & 0,232 \\
Nursery & Nursery & 5957 & 597774 & 0,788 & 0,645 \\
Certified-Swine-Breeder-Farm & Finisher & 5436 & 1217011 & 0,719 & 1,314 \\
Wean-to-finisher \& mixed & Finisher & 5122 & 945689 & 0,677 & 1,021 \\
Non-Comercial & Slaughterhouse & 4281 & 49196 & 0,566 & 0,053 \\
Finisher & Breeding-farm & 2668 & 37294 & 0,353 & 0,04 \\
Certified-Swine-Breeder-Farm & Nursery & 2498 & 730581 & 0,33 & 0,789 \\
Wean-to-finisher \& mixed & Nursery & 2326 & 913646 & 0,308 & 0,986 \\
Wean-to-finisher \& mixed & Certified-Swine-Breeder-Farm & 1821 & 693303 & 0,241 & 0,748 \\
Others & Breeding-farm & 1681 & 13438 & 0,222 & 0,015 \\
Certified-Swine-Breeder-Farm & Wean-to-finisher \& mixed & 1238 & 32737 & 0,164 & 0,035 \\
Wean-to-finisher \& mixed & Wean-to-finisher \& mixed & 823 & 51564 & 0,109 & 0,056
\end{tabular}




\begin{tabular}{llllll}
\hline Origin & Destination & movements & Animals & mov. percentage & Ani. pe \\
\hline Breeding-farm & Wean-to-finisher \& mixed & 792 & 120578 & 0,105 & 0,13 \\
Finisher & Nursery & 558 & 61907 & 0,074 & 0,067 \\
Others & Slaughterhouse & 558 & 18618 & 0,074 & 0,02 \\
Non-Comercial & Non-Comercial & 481 & 2658 & 0,064 & 0,003 \\
Breeding-farm & Breeding-farm & 457 & 7913 & 0,06 & 0,009 \\
Non-Comercial & Breeding-farm & 423 & 5277 & 0,056 & 0,006 \\
Nursery & Non-Comercial & 416 & 23460 & 0,055 & 0,025 \\
Non-Comercial & Finisher & 371 & 58790 & 0,049 & 0,063 \\
Breeding-farm & Certified-Swine-Breeder-Farm & 310 & 77071 & 0,041 & 0,083 \\
Others & Wean-to-finisher \& mixed & 292 & 5345 & 0,039 & 0,006 \\
Non-Comercial & Nursery & 271 & 21080 & 0,036 & 0,023 \\
Breeding-farm & Non-Comercial & 267 & 21617 & 0,035 & 0,023 \\
Wean-to-finisher \& mixed & Non-Comercial & 263 & 5962 & 0,035 & 0,006 \\
Finisher & Certified-Swine-Breeder-Farm & 249 & 6567 & 0,033 & 0,007 \\
Others & Certified-Swine-Breeder-Farm & 218 & 4246 & 0,029 & 0,005 \\
Finisher & Non-Comercial & 194 & 4717 & 0,026 & 0,005 \\
Finisher & Wean-to-finisher \& mixed & 161 & 6071 & 0,021 & 0,007 \\
Nursery & Wean-to-finisher \& mixed & 155 & 27453 & 0,021 & 0,03 \\
Certified-Swine-Breeder-Farm & Others & 144 & 10512 & 0,019 & 0,011 \\
Breeding-farm & Others & 134 & 16330 & 0,018 & 0,018 \\
Wean-to-finisher \& mixed & Others & 63 & 2801 & 0,008 & 0,003 \\
Finisher & Others & 57 & 2134 & 0,008 & 0,002 \\
Certified-Swine-Breeder-Farm & Non-Comercial & 52 & 629 & 0,007 & 0,001 \\
Nursery & Others & 51 & 11436 & 0,007 & 0,012 \\
Others & Finisher & 39 & 2512 & 0,005 & 0,003 \\
Nursery & Certified-Swine-Breeder-Farm & 23 & 7760 & 0,003 & 0,008 \\
Non-Comercial & Wean-to-finisher \& mixed & 22 & 223 & 0,003 & 0 \\
Others & Non-Comercial & 11 & 33 & 0,001 & 0 \\
Others & Nursery & 8 & 88 & 0,001 & 0 \\
Non-Comercial & Others & 7 & 151 & 0,001 & 0 \\
\hline & Others & 2 & 0 & 0 \\
\hline
\end{tabular}

